\title{
Strategic sourcing and procurement of facilities management services
}

\author{
Jensen, Per Anker
}

Published in:

Journal of Global Operations and Strategic Sourcing

Link to article, DOI:

10.1108/JGOSS-10-2016-0029

Publication date:

2017

Document Version

Peer reviewed version

Link back to DTU Orbit

Citation (APA):

Jensen, P. A. (2017). Strategic sourcing and procurement of facilities management services. Journal of Global Operations and Strategic Sourcing, 10(2). https://doi.org/10.1108/JGOSS-10-2016-0029

\section{General rights}

Copyright and moral rights for the publications made accessible in the public portal are retained by the authors and/or other copyright owners and it is a condition of accessing publications that users recognise and abide by the legal requirements associated with these rights.

- Users may download and print one copy of any publication from the public portal for the purpose of private study or research.

- You may not further distribute the material or use it for any profit-making activity or commercial gain

- You may freely distribute the URL identifying the publication in the public portal

If you believe that this document breaches copyright please contact us providing details, and we will remove access to the work immediately and investigate your claim 


\title{
STRATEGIC SOURCING AND PROCUREMENT OF FACILITIES MANAGEMENT SERVICES
}

\author{
Per Anker Jensen \\ Technical University of Denmark
}

\begin{abstract}
Purpose: The purpose it to provide insights into strategic sourcing concerning Facilities Management (FM) and how it can contribute to a sourcing decision that combines the benefits of internal and external provision with consideration of business risk and cost.

Design/methodology/approach: The paper investigates a strategic sourcing and procurement process in a large public organisation in Denmark based on participating in internal meetings, a workshop, document studies and interviews. The process is compared to a new ISO standard with guidance on strategic sourcing and development of FM agreements.
\end{abstract}

Findings: A problem in the new ISO standard is that it is based on sequential model starting with detailing the demand and needs before investigating sourcing option. The case shows that the way needs are specified are depending on the chosen sourcing models. Based on a thorough analysis the organisation decided to change the sourcing strategy with insourcing the most critical building related activities and changing the procurement strategy from one integrated FM contract to 3 bundled and 7 single service contracts. The concept of right-sourcing is discussed.

Research limitations/implications: The research is based on a study of one public organisation, which limits the possibility to generalise the results. However, it provides detailed insights into the strategic sourcing process in FM, which can give inspiration for practitioners and further research.

Originality/value: The paper throws light on a strategic sourcing process which is rarely available in public due to confidentiality considerations and it provides the first evaluation of the new ISO standard from 2016.

\section{INTRODUCTION}

Outsourcing is closely connected to the development of Facilities Management (FM). For some people FM is even regarded as the same as outsourcing. This is particularly the case in connection with IT, where FM is often used specifically for outsourced solutions. However, in the broader understanding of FM as the management of the support functions in organisations concerning physical facilities and related internal services outsourcing is merely one of possible ways of delivering FM services. A new ISO standard on FM vocabularium defines FM as: "organizational function which integrates people, place and process within the built environment with the purpose of improving the quality of life of people and the productivity of the core business" (ISO, 2016a).

The degree of outsourcing in FM has been steadily increasing in many countries over the last decades. This has led to the development of a model for FM market maturity, where the degree of outsourcing is the decisive factor for measuring maturity, and the model has been used to 
classify the maturity of the FM market in all European countries (Teichmann, 2009). The Netherlands is one of the pioneering FM markets in Europe and therefore among the most mature market. It is also one of the most frequently investigated markets. Studies of the market size every second year has shown that the degree of outsourcing even continued to increase during the financial crisis from $63 \%$ in 2009 to $64 \%$ in 2011 even though the total turnover of FM was slightly reduced (van der Spil, 2013).

Thus, decisions about sourcing are essential aspects of FM. There has been a considerable amount of research about whether to outsource or not and how to do procurement and outsourcing. There has been less research on how to conduct a strategic sourcing process leading to an informed decision between the different sourcing options. This paper investigates the process of strategic sourcing and procurement of FM based on literature review and a study of a large public organisation in Denmark. The purpose it to provide insights into strategic sourcing concerning FM and how it can contribute to a sourcing decision that combines the benefits of internal and external provision with consideration of business risk and cost.

Strategic sourcing is theoretically related to the classical corporate management question of making or buying and related to this, coordination based on corporate organisation (hierarchy) or market (Williamson, 2008). The question can be seen as a narrow and short term economical question of finding the cheapest solution, but it can also be regarded as a strategic issue, where long term benefits and risks are more in focus. As many organisations have achieved increased experience with outsourcing of FM, the strategic view seems to become more important. One sign of this is that the new standard ISO (2016b) originally aimed at updating a European standard EN 15221-2 (CEN, 2006b) with guideline on FM agreements now also includes guidance on strategic sourcing.

The paper starts with a literature review in the next section. This is followed by sections on methodology and empirical findings. The paper is finished with analysis, discussion and conclusions.

\section{LITERATURE REVIEW}

One of the first research papers on sourcing strategies in FM was Hui and Tsang (2004), who identified four sourcing strategies: Insourcing, outsourcing for cost efficiency, outsourcing for capability, and out-tasking. The distinction between outsourcing and out-tasking is very common in FM literature. Out-tasking concerns single services with one provider for each service, while outsourcing concerns multiple services bundled in larger contracts. Hui and Tsang (2004) also state that out-tasking is focused on productivity and insourcing is focused on core competencies. Sourcing strategy is for Hui and Tsang (2004) basically a question of choosing between the four different service delivery options. They do not present a process for developing a sourcing strategy, but they divide the implementation of a sourcing strategy after choice of strategy into a process with five phases: Planning, setting of performance standards, work transactions, performance review, and review of strategy.

Ventovuori (2007) conducted a study in Finland about sourcing strategy, where he developed an integrated approach with a framework for the development of sourcing strategy in FM services. The framework included five different categories for which the client must make a decision under consideration of the FM service market and the business. The five categories and the main distinctions for each category are (Ventovuori, 2006): 
1. Sourcing interface: In-house production, in-house sourcing and external sourcing

2. Organizational decision-making: Decentralised or centralised organization

3. Scope of service package: Single or bundled services

4. Geographical area of sourcing: Single site or regional

5. Relationship type: Arm's length relationship or partnering

Ventovuori and Lehtonen (2006) extended the relationship types by dividing partnering in operational and strategic partnering and present a sourcing portfolio model consisting of: Arm's length relationship, operational partnering, strategic partnering and in-house production. Operational partnering is characterized among other things by bundling of sites and services, while strategic partnering is characterized among other things by including management services. Thus, strategic partnering resembles what is also called Integrated FM (I-FM). Inhouse production is seen as full vertical integration.

A study of the FM market in Denmark, Finland, Iceland, Norway and Sweden indicated that IFM was the dominating form of outsourcing in the Nordic countries of Europe and also was the fastest growing part of the market (Capgemini, 2005). There is also a clear trend towards multinational companies increasingly making I-FM contracts across borders with international operating FM providers (Jensen, 2012). Plane and Green (2011) from the UK perceived a shift towards the adoption of "relational" procurement processes for awarding FM contracts. The results of their interview survey among buyers and suppliers support the view that a relational procurement process provides greater clarity of service requirements and facilitates cultural alignment between the buyer and supplier, but additional time, effort, and cost are incurred. Concerns also arose regarding the maturity of the supplier market and the sincerity of the client intentions to collaborate.

Redlein and Zobl (2014) investigated FM outsourcing statistically based on national surveys in Austria. They concluded that most outsourced facility services are cleaning, winter service, heating/ventilation/air condition and outdoor area. Most of the client companies had between 3 to 10 external service providers. The annual savings for companies with 3 to 10 external service providers were higher than for companies with less and with more providers. However, the correlation is weak between the number of external service providers and the degree of outsourcing and the annual savings. Although organizations may outsource for cost related reasons, there are no guarantees that expected savings will be realized. Determinants of outsourcing decision for FM services provision were investigated by Ikediashi et al. (2014) based on a questionnaire survey among commercial banks in Nigeria. Out of 25 investigated criteria they found that 14 factors were significant in explaining the reason for outsourcing. The most important factor was "to improve company's focus" followed by "to make cost transparent" and "to improve stakeholders' satisfaction".

Lok and Baldry (2015) investigated outsourcing relationships in higher education institutions in Hong Kong applying a framework called FORT developed for the IT industry. In relation to FM they distinguish between the four relationship types: In-house, technical expertise, service commitment, and common goals. Based on a questionnaire survey they investigated the frequency of these relationship types for four different FM services: Building maintenance, security, cleaning, and catering, based on evaluations of four relationship dimensions: Ownership of FM assets, control over FM assets, competitive position, and long-term planning. This is the only study found that examines a range of different relationship types for individual FM services. 
The development in FM research on strategic sourcing shows that there has been clear development from seeing strategic sourcing as a basic choice between different methods of service provision towards regarding strategic sourcing as a process with a number of dimensions that needs to be evaluated and decided on with consideration of the business environment and the FM market. The number of different sourcing options presented in FM research has not changed much. Most studies include 4 options often presented in a two-by-two matrix. However, there is a general trend towards less in-house provision and outsourcing and relational contracts including management services becoming more common. Sourcing strategies with a combination of different sourcing solutions are rarely studied.

In general the possible sourcing options are much wider than presented in FM research. Kate Vitasek from the University of Tennessee has developed the concept of Vested outsourcing as an outcome and partnership based collaboration between client and provider, which has received interest in FM as well as in other service industries. In a recent general review paper Vitasek (2016) writes, that organizations should view sourcing as a continuum rather than a simple market-based make versus buy decision. This is based on the seminal work on Transaction Cost Economics by Oliver E. Williamson, who was awarded the Nobel Prize in 2009. Williamson (2008) recommends that organisations should use contracts that are "hybrids" between purely transactional market based contracts and purely hierarchy based provisions for complex contracts. Vitasek (2016) presents seven sourcing business models with two being transactional (basic provider model, approved provider model), three being relational (preferred provider model, performance-based/managed services model, vested business model), and two being investment (shared services model, equity partnership model). The transactional models are purely market-based and the investment models are hierarchy models, while the relational models are hybrids. In the analysis section later in the paper these models are compared with sourcing models and relationship types in other literature and in the case study, see Table 3.

The increasing complexity in strategic sourcing is reflected in the new ISO standard. Standardisation in FM started in Europe, where the first two standards were adopted in 2006 concerning terms and definitions (CEN, 2006a) and guidance on how to prepare FM agreements (CEN, 2006b). More recently international standardisation activities in FM started and the first work items concerned developing global standards on the same topics as the first two European FM standards. This has resulted in the two first ISO standards (ISO, 2016a+b). A major new development is that the standard concerning FM agreements has been extended by including guidance on strategic sourcing. The standard ISO (2016b) includes a sourcing process with 10 main phases:

1. Sourcing strategy and core business context

2. Identify current and future needs

3. Translate needs into requirements

4. Describe the Service Levels

5. Identify service delivery options

6. Business case development

7. Select preferred sourcing/service delivery option

8. Facilities service provision

- Internal service provision

- External service provision

9. FM service procurement \& FM Agreement 
10. Measure service provision performance

\section{METHODOLOGY}

The background for this research was that the researcher was contacted as FM expert by the newly employed project manager for the strategic sourcing process in the case organisation Danish Broadcasting Corporation (DR) - in November 2014 to get general information and views on the development of FM. As a result of this contact and further meetings with the FM contract management unit in the case organisation is was agreed that the researcher could get ongoing access to information from the sourcing process and participate as observer at internal meetings as part of a research study. DR is a public organisation and was willing to share their experience with the strategic sourcing and procurement process and have them published in a scientific paper after the process was completed. The researcher made a confidentially agreement with the case organisation before starting the research.

The case study is based on meetings with the internal FM contract management unit, participation as observer in a start-up workshop for the strategic sourcing process, document studies and interviews with the head of the unit and the project manager of the strategic sourcing and procurement process. Minutes from the interviews were sent to the interviews for commenting and approval. The publication of this paper has been approved by the DR.

\section{FINDINGS}

DR is an independent public institution financed by license fees and provides radio, television and online media services in Denmark and has about 3,000 employees. DR relocated its activities in the Copenhagen area from 12 former addresses to a new headquarters called DR Byen (DR City) in the period 2006-2009. DR-Byen is a complex of approx. $132.000 \mathrm{~m}^{2}$, which includes a concert hall with public performances. Besides, DR has smaller facilities in provincial towns around Denmark.

DR has a long history of outsourcing FM services, see Figure 1. In the early 1990's DR's cleaning contract with ISS (Danish based multinational FM service provider) had be running for 50 years without being put out for tender (Jensen, 2008). This changed after an integrated internal FM function headed by a service manager was established in 1994. Cleaning was put out for public tendering in accordance with EU procurement regulations resulting in large cost savings, but also with initial problems with the quality of cleaning. Catering was also put out for public tendering resulting in outsourcing of catering in the cantinas in Copenhagen, while a bid from the internal catering team was accepted in another cantina. Otherwise most FM services were in-house before 2006.

Before relocating to the new headquarters DR Byen it was decided to make a comprehensive outsourcing of all cleaning and catering in a bundled contract with one provider. This resulted in a contract with ISS for the period 2006-2010 resulting in substantial cost savings. In a next round of public tendering it was decided to extend the contract much further. The intention was to create as large a volume as possible to achieve maximum cost savings. A main reason was budget overrun on the headquarters building project, but there also was a desire in DR's top management to professionalize the property management and competitive tendering was seen as a mean to achieve that. Therefore near enough all FM services became part of the scope, and 
the volume was more than double compared to the former contract. Maintenance planning and technical building operation were for instance included. The result was an I-FM contract with Coor Service Management (Swedish based service provider with strong focus on I-FM contracts in the Nordic countries - originally called Skanska-FM). The contract period was 2011-2015. It was the largest I-FM contract made in Denmark.

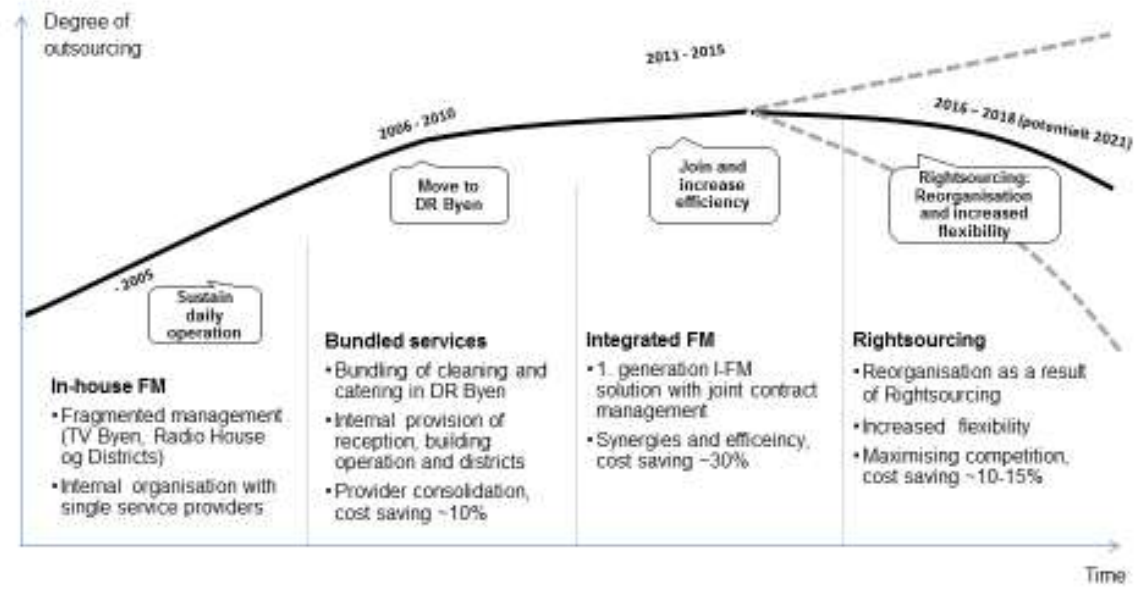

Figure 1: The history of outsourcing in DR (Source: DR)

\section{$D R$ 's evaluation of the former I-FM collaboration}

As a basis for starting the strategic sourcing process leading up to a new procurement round in 2015 DR made a thorough evaluation in autumn 2013 of the ongoing I-FM collaboration with Coor Service Management. The following is mostly based on document studies and interview 28 May 2014 with the head of the FM contract management unit, who came to DR in March 2012 as manager of DR's FM department called DR Estates and Services.

When the contract period started by 1 January 2011 most staff working for ISS under the former contract was transferred to the new provider as part of the transition. The first part of the contract period was an implementation process of the contract with the new provider, and DR faced many problems in getting a satisfactory service provision and collaboration with the new provider. The implementation period was still ongoing, when the current head of DR Estates and Services was engaged in March 2012. It was not before about a year later - almost half way during the contract period - that most trouble-shooting had been sorted out and a more development oriented phase directed towards optimising the service provision could start. After about three years in the contract period preparation for contract termination started with monthly transition meeting between DR and the provider with the aim to retain staff, resolve disagreements and prepare time schedules.

Examples of specific problems in the implementation phase were that it took two years before DR got reasonable insight into the provider's plans for building maintenance and investments and it took three years before DR received satisfactory plans for preventive maintenance of the headquarters and proposals for energy optimisations. It was also discovered that the interphases between the providers IT systems and DR systems were much more complicated than expected; partly due to DR's policy for IT security. DR decided to use options to withdraw minor parts of the services from the contract, but it turned out to be more difficult than expected to change 
the contract, because the provider had integrated all the services in the contract in their central service centre system. DR's contract manager found that an I-FM provider is "too big to fail".

An I-FM contract is in principle based on a single point of contact between client and provider. This turned out to be far from reality, because the provider is organised with a number of internal cost centre with each their budget responsibilities and DR had to negotiate and have contact with many different parties and management levels in the provider organisation. The monthly contract management meeting typically included 5 persons from DR and 9 from the provider. Besides there were weekly contract meetings between DR's and the provider's contract manager and between the persons on each side responsible for each of the main service areas: 'cleaning', 'catering', 'building technic', and 'soft service'. A quarterly steering group meeting were held with the CFO and contract manager from DR and the Danish CEO, a deputy director and the contract manager from the provider.

The contract included a main part with a fixed fee and other parts with payment per project or service order. The fixed fee was reduced with 1 million DKK per year (slightly more than $1 \%$ of the fixed fee) over the contract period without reducing service quality. The provider was obliged to prepare a catalogue each year with proposals for such savings to be accepted by DR. From hindsight DR evaluates that they altogether achieved a saving by $20-30 \%$ by making the I-FM contract. Only about two thirds of the initial expected savings were achieved, but the savings were still substantial. It is DR's impression that the provider made a very low bid to get a better foothold on the Danish market with a large contract.

A major problem seen from DR's perspective was the technical building area. DR found that the provider did not have the relevant competences and resources on the overall strategic level to be sufficiently prepared for unexpected incidents in relation to building technic. There were some serious incidents during the contract period with cut out of electricity and cooling supply, which showed that the necessary people and competences in the providers' organisation were not in place. DR found that the provider had reduced the amount of staff in this area to an unacceptable level both on strategic and operational level.

Cost reduction was the main criteria in DR's evaluation over the tenders for the I-FM contract. In spite of that the contract was still formulated with intentions of a partnership with a collaboration based on mutual trust and working towards common goal. There were workshops arranged between the two parties to create team building and a joint spirit of partnership. The contract was also to a certain degree formulated with function or output based requirements, which leaves freedom to the provider to choose work processes, rather than input or instruction based requirements. However, the different economic interests showed to be decisive, so a partnership spirit could not be developed and DR found that they had to rely more on control of the service provision than on trust in the provider. DR's contract manager also came to the conclusion that the fact that service contracts at least for a public organisation has to be time limited and put out for public tender after a few years prevents the development of true partnerships. But independent of that it is still important for both parties to build a good working relationship with each other to get the best out of the collaboration for both parties.

Even though the I-FM collaboration in some areas has been unsatisfactory, there have also been many areas where it has worked well. DR's contract manager reckons that there probably would have been similar problems, if they had chosen another I-FM provider. His reflection was, that when one focuses narrowly on getting cost reductions, you cannot expect to get a high service 
quality at the same time. DR made a strategic mistake by promising their staff the same service level as before the contract. One does not achieve that level of cost saving without a sacrifice.

The strategic sourcing process

DR defined the purpose of the strategic sourcing and procurement process as:

1. Make a thorough analysis of the FM area (including evaluating the present FM procurement to gain as much learning as possible for the new procurement)

2. Decide the optimal scope for the new procurement

3. Make new agreement(s), which ensure a high degree supply security

4. Make new agreement(s), which ensure a satisfactory quality and service level

5. Make new agreement(s), which ensure that the total economic frame for FM provision as far as possible is kept

6. Make new agreement(s), which ensure that DR fulfil its legal obligation for public procurement on the area and that DR get the best possible agreement conditions

The whole process was divided in five phases with the following periods:

1. Planning and project establishing (September 2013 - February 2014)

2. Sourcing analysis (December 2013 - May 2014)

3. Preparing of tender material (March 2014 - November 2014)

4. Tendering process (August 2014 - October 2015)

5. Implementation and transition (October 2015 - June 2016)

The project group consisted of the project manager from DR Estates and Services and a person from the procurement unit in the financial department. The project group also involved an external consultant from the company fm3.dk specialised in FM consulting. A steering was established chaired by the Financial Director, the head of DR Estates and Services and the head of the procurement unit. Besides, the project work involved the staff in DR Estates and Services as well as super users from a number of other departments in DR.

The strategic sourcing covered the second of the five phases and was finished with the acceptance by DR's board of directors of a report with sourcing analysis and strategy for FM; including the recommendation for scope of the procurement process. The following is mostly based on participation as observer in an internal kick-off workshop in DR 27 January 2014 facilitated by an external consultant, interview with DR's project manager 28 September 2015 and document study of the above mentioned report and related documents. It should be noted that most of the analysis is case-specific and should not be transferred to other cases without giving necessary considerations to the case-specific context and implications.

A fundamental part of the strategic sourcing analysis was to analyse each of 12 main service areas in relation to what the degree each service was evaluated in relation to the following 8 seven criteria:

1. Is critical for DR's core business

2. Is strategic/tactical for DR

3. Influences the strategic/tactical FM

4. Insourcing would set requirement for DR's competences

5. Impacts DR's staff

6. Impacts DR's guest 


\section{Can devaluate DR's assets if not performed optimally}

The results of the analysis were presented in a so-called right-sourcing matrix, where traffic lights showed, whether a service was evaluated high (red), medium (yellow) or low degree (green), see Figure 2. The service area 'building technic' stood out as the only one where all criteria were evaluated either high or medium.

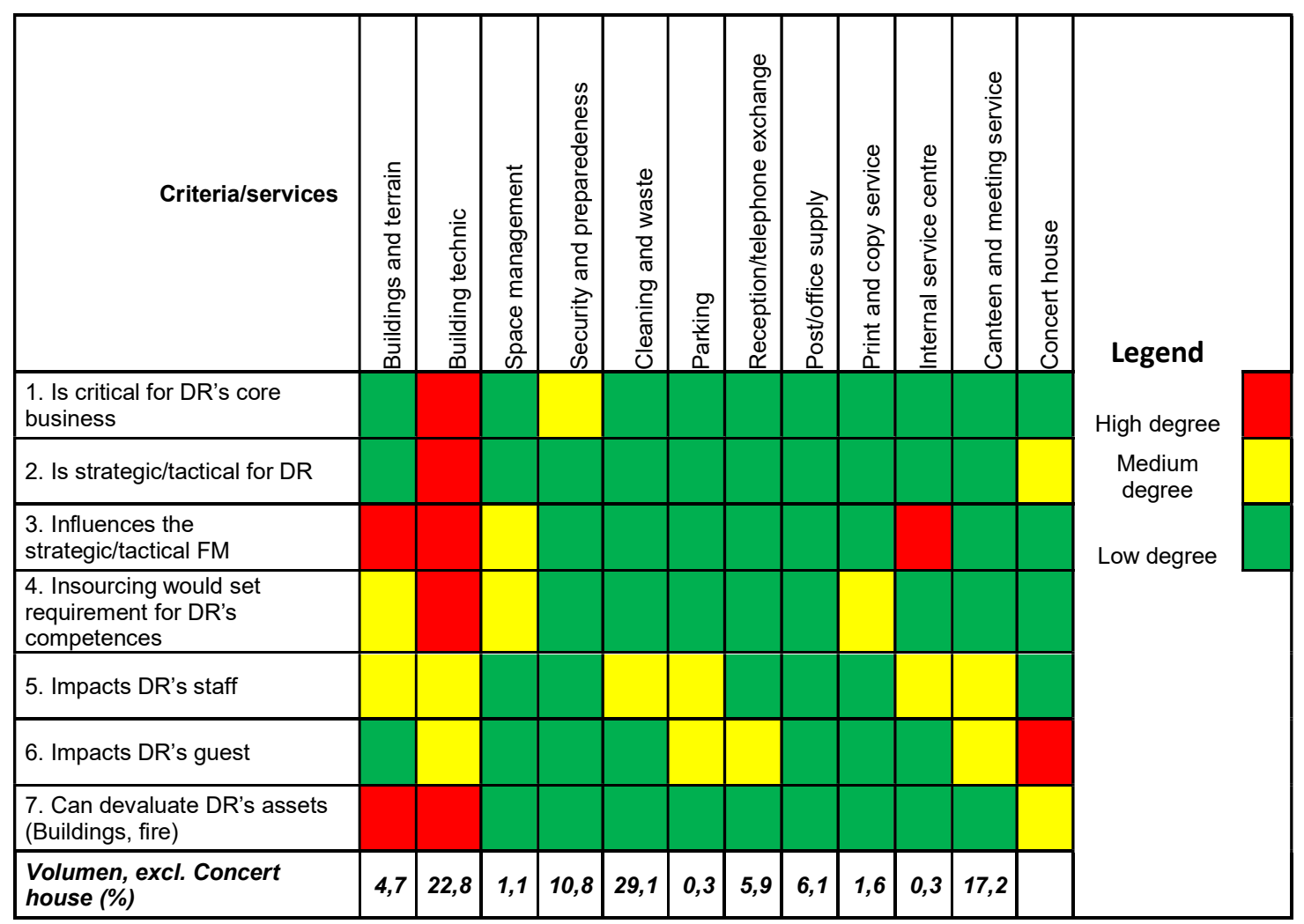

Figure 2: Right-sourcing matrix for FM services in DR (Source: DR, based on a template developed by Preben Gramstrup, fm3.dk)

Another element in the analysis of the different services was using a priority triangle to evaluate what was most important for each service in terms of the three criteria: User satisfaction, supply security, and economy, see Figure 3. The service area 'cleaning and waste' stood out as having highest priority in relation to user satisfaction, while 'building technic' had highest priority in relation to supply security, and 'parking' was the service where economy had highest priority. The priority triangle was also used on a more detailed level to analyse which aspect in relation to a specific service area had different priority concerning the same three criteria as part of defining the more specific requirements for the tender material. 


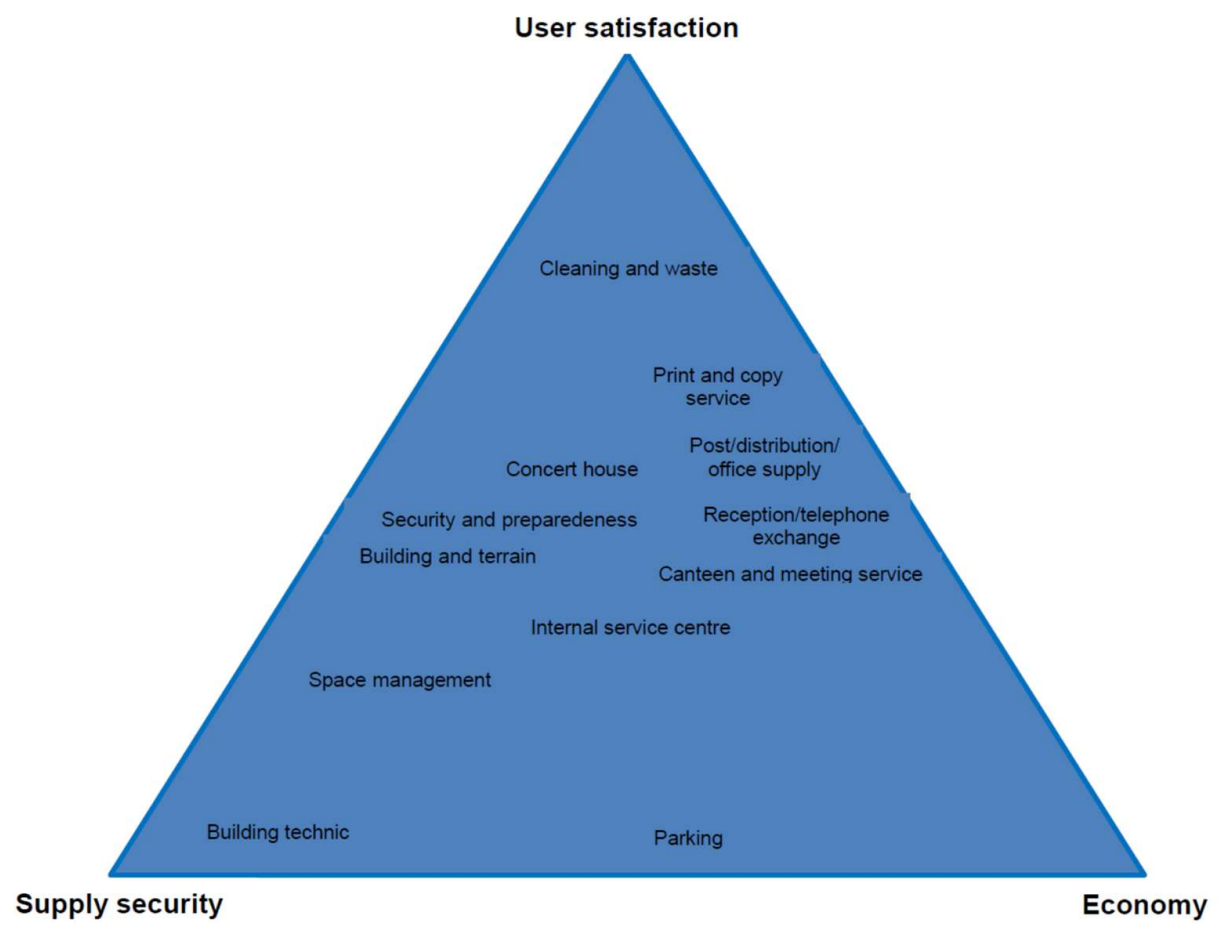

Figure 3: Priority triangle for FM services in DR (Source: DR, based on a template developed by Preben Gramstrup, fm3.dk)

The possibility to achieve synergies between different work processes by bundling different service areas was analysed from an 'inside-out' perspective by use of a proximity matrix similar to what is often used for space briefing to analyse proximity between different functions, areas or rooms, see Figure 4. In the matrix all service areas are listed both horizontally and vertically and traffic lights are used like in the right-sourcing matrix (except that only the boxes above or below the diagonal needs filling in due to symmetry). The results showed that synergies were mostly found between the service areas 'building and terrain', 'building technic', space management' and 'security and preparedness' and between the service areas 'reception/telephone exchange', 'internal service centre' and 'security and preparedness'. All synergies were found to be connected to operational processes with a high degree of shared operational activities. The service area 'security and preparedness' has a special importance and large economic volume because the fire prevention strategy in the complex implies that two so-called firefighters have to be on duty on a $24 / 7$ basis.

The analysis of bundling was supplemented by an 'outside-in' perspective as part of a market analysis, which applied the classic sourcing model developed by Krajlic (1983). This model is in its simplest form a 2 x 2 matrix with profit or value impact (low - high) for the company on one axis and market supply risk or complexity (low - high) on the other axis. Items with high impact and high risk are seen as strategic, where make or buy consideration should be in focus. Items with low impact and low risk are seen as non-critical, where product standardisation should be in focus. High impact combined with low risk is characterizing items suitable for leverage or competition with full exploitation of purchasing power with high requirements. The last square with low impact and high risk is characterized as bottleneck, where control of vendors and back up plans should be considered. 


\begin{tabular}{|c|c|c|c|c|c|c|c|c|c|c|c|c|c|}
\hline $\begin{array}{l}\text { Synergies in } \\
\text { relation to work } \\
\text { processes }\end{array}$ & 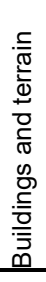 & 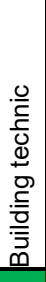 & 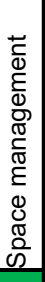 & 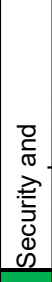 & \begin{tabular}{|c|}
0 \\
0 \\
0 \\
0 \\
3 \\
0 \\
0 \\
0 \\
0 \\
0 \\
.$\frac{5}{C}$ \\
$\mathbb{0}$ \\
$\frac{0}{0}$ \\
0
\end{tabular} & 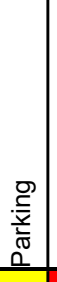 & 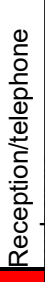 & 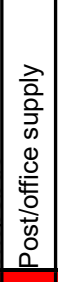 & 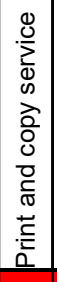 & 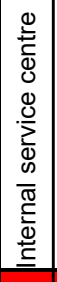 & 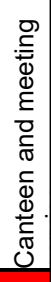 & 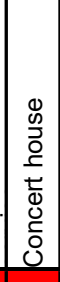 & Legend \\
\hline Buildings and terrain & & & & & & & & & & & & & $\begin{array}{l}\text { High } \\
\text { level }\end{array}$ \\
\hline Building technic & & & & & & & & & & & & & $\begin{array}{l}\text { Medium } \\
\text { level }\end{array}$ \\
\hline Space management & & & & & & & & & & & & & $\begin{array}{l}\text { Low } \\
\text { level }\end{array}$ \\
\hline $\begin{array}{l}\text { Security and } \\
\text { preparedeness }\end{array}$ & & & & & & & & & & & & & \\
\hline Cleaning and waste & & & & & & & & & & & & & \\
\hline Parking & & & & & & & & & & & & & \\
\hline $\begin{array}{l}\text { Reception/telephone } \\
\text { exchange }\end{array}$ & & & & & & & & & & & & & \\
\hline Post/office supply & & & & & & & & & & & & & \\
\hline $\begin{array}{l}\text { Print and copy } \\
\text { service }\end{array}$ & & & & & & & & & & & & & \\
\hline $\begin{array}{l}\text { Internal service } \\
\text { centre }\end{array}$ & & & & & & & & & & & & & \\
\hline $\begin{array}{l}\text { Canteen and } \\
\text { meeting service }\end{array}$ & & & & & & & & & & & & & \\
\hline Concert house & & & & & & & & & & & & & \\
\hline
\end{tabular}

Figure 4: Synergies between work processes for FM services in DR (Source: DR and Preben Gramstrup, fm3.dk)

In the case project the $2 \times 2$ matrix was used in a way where the services were evaluated and plotted on an $\mathrm{x}-\mathrm{y}$ diagram with continuous axes. A diagram was produced for each service with a division in sub-services. Figure 5 shows an overview diagram with each of the services and some of the most important sub-services.

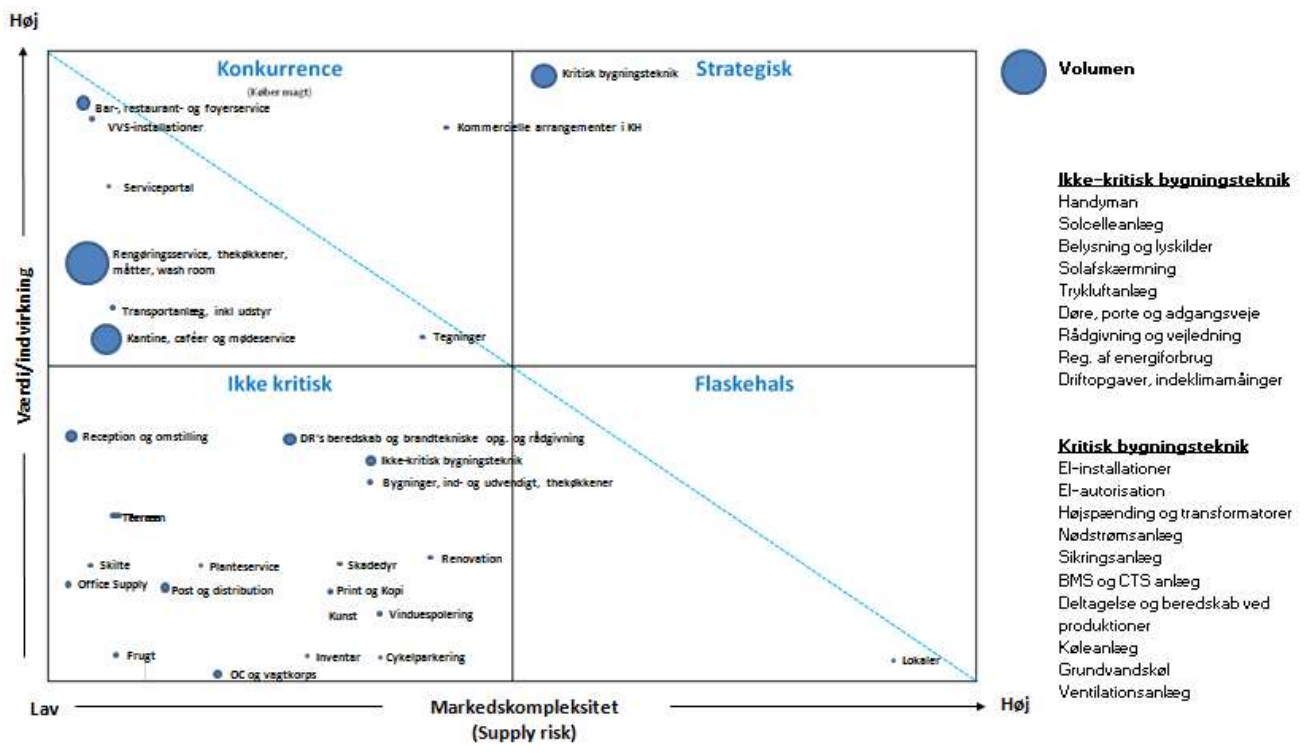

Figure 5: Overview of FM services in DR analysed by use of Krajlic's model (Source: DR) 
The analysis showed that most services were seen as non-critical. The only bottleneck item was 'space planning' and even though this had been included in the original I-FM contract, it had been insourced during the contract period and it was recommended to keep it in-house. The square with leverage or competition included some part of 'building operation' and some services related to the concert hall. The only services in the strategic square were critical parts of 'building technic'. A detailed analysis was made to distinguish between critical and noncritical 'building technic'. The result is shown in Table 1 .

Table 1: Building technic in FR divided in critical and non-critical items (Source: DR)

\begin{tabular}{|l|l|}
\hline Critical building technic & Non-critical building technic \\
\hline Electrical installations & Handyman \\
Electrical authorization & Photo-voltaic system \\
High voltage and transformers & Lighting and light sources \\
Emergency supply systems & Solar screens \\
Security systems & Air pressure systems \\
Building management and control systems & Doors, gates and access routes \\
Participation and preparedness during media production & Consulting and advice \\
Cooling systems & Regulation of energy consumption \\
Ground water cooling & Operational tasks, measuring indoor climate \\
Ventilation systems & \\
\hline
\end{tabular}

The market analysis also included meetings and consultations with a large number of companies and experts to collect knowledge about current market situation and experiences with different sourcing and procurement solutions seen from the demand and supply side as well as by independent observers. This included 12 client organisations with both public and private Danish corporations, 9 provider companies covering both large all-round FM providers and more specialised service providers, and 4 expert organisations. The market research also included the preparation of a broad overview of potential providers, which was presented in a provider matrix mapping which providers were likely to be able to offer the different bundles of services that the project group was recommending. This was done to check and verify that the recommended bundles would attract a sufficient number of potential tenderers to create the intended competition.

The analysis defined the following 4 sourcing models:

- In-house/own production

- Singles services

- Bundled services

- I-FM

The models were compared according to a number of criteria, see Figure 6 . All the models were regarded to be able to fulfil requirement concerning high user satisfaction, flexibility, possibility for benchmarking, and a simple and clear monitoring by KPI's. I-FM was evaluated problematic in relation to possibility to change provider and to create a transparent pricing model. In-house was evaluated as less optimal with regards to the same two criteria as well as concerning to keep within the economical frame. Single services were evaluated as less optimal with regards to a controlled implementation and security for supply of FM services. There were no reservations for any of criteria for bundled services. In relation to the size of the own FM organisation, it was evaluated to be big for in-house provision and small for I-FM and bundled services, while it for single services was evaluated as small/medium depending on number of actually single service providers. 


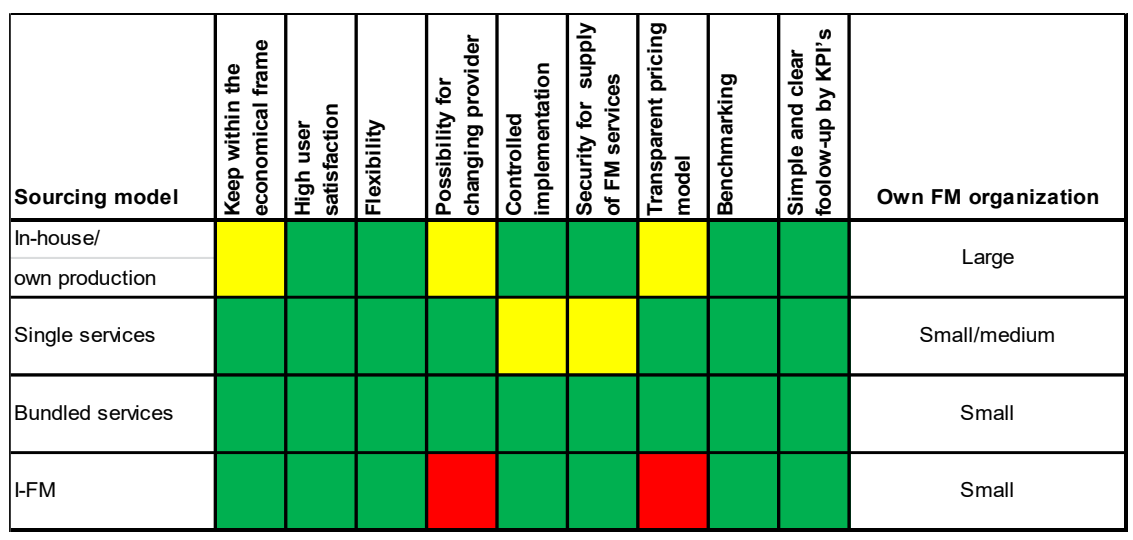

Figure 6: Sourcing models evaluated in DR's analysis. Green: Fulfilled; Yellow: Possible but not optimal; Red: Difficult to get fulfilled. (Source: DR and Preben Gramstrup, fm3.dk)

The mentioned sourcing models were mostly seen as relevant for activities that are concurrent. Smaller ad hoc activities could also be included based on unit prices, for instance cleaning after special event. For larger tasks and projects it could be advantageous to put them out for tender individually or based on a frame agreement with a limited number of selected providers. This was for instance seen as relevant for larger maintenance activities and for commercial events in the concert house

The analysis was synthesized in the presentation and evaluation of 3 alternatives for scope of in-house versus outsourcing. The overall scope of FM was defined with a division in strategic, tactical and operational level in the services listed in Table 2.

Table 2: FM services in DR on strategic, tactical and operational level (Source: DR, based on a template developed by Preben Gramstrup, fm3.dk)

\begin{tabular}{|l|l|}
\hline Level & Services \\
\hline Strategic: Frames and objectives & FM strategies \\
& Frames for SLA's and KPI's \\
\hline Tactical: Processes and planning & Benchmarking \\
& Contract management \\
& Procurement of FM services \\
& Space optimisation and usage \\
& Follow-up on provisions \\
& Quality assurance \\
& Planning \\
& Improvement/innovation \\
& Insurance \\
\hline Operational: Provision and execution & Cleaning \\
& Service centre \\
& Security \\
& Building technic and property operation \\
& Catering and meeting service \\
& Post and distribution \\
& Reception and telephone exchange \\
& Concert house \\
\hline
\end{tabular}


The three alternatives were

1. DR provides all FM services in-house, i.e. all services in Table 2

2. DR only provides the strategic tasks and a few of the tactical tasks, i.e. benchmarking and contract management

3. DR provide all strategic, tactical and the most important operational task, i.e. service centre, building technic and property operation, and concert house

The project group evaluated the three alternatives in relation to the success criteria mentioned earlier. The result was a recommendation of alternative 3. Main arguments against alternative 1 were that the success criteria concerning economy and security for service provision could not be fulfilled and even though the internal FM organisation would be big, it would still not have sufficient critical mass for all service areas to be efficient. Main arguments against alternative 2 were that the success criteria concerning flexibility and possibility for continuous competition were not fulfilled and that DR would have a lack of control over data and not be able to proactively develop the FM area on their own. An important precondition for recommending alternative 3 was that DR established and managed their own helpdesk and service portal.

The result was a recommendation of a sourcing solution with a combination of insourcing, bundled outsourcing and single service outsourcing (out-tasking). The insourcing covered an economic volume of $9 \%$ of the I-FM contract and covered the tactical part of building operation as well as the operational functions: handyman, heating, ventilation and air-conditioning (HVAC), and service portal. Besides, earlier insourced activities concerning space management, projects, and bar and foyer service in concert house was recommended to stay inhouse.

The bundled services covered the main economic volume with $70 \%$ of the I-FM contract. The services were divided in 3 contracts: 'Catering', 'Security and internal service', and 'Cleaning'. Even though catering and cleaning could be regarded as single services, the contracts had large volumes and included many sub-services and all DR's locations for cleaning and the two main locations for catering.

The single services included 7 separate contracts together covering the remaining economic volume of $21 \%$ of the I-FM contract. The single service contracts were 'Building technic' (only frequent and legal required inspections and service operations), 'Terrain', 'Pest control', 'Waste handling', 'Fruit provision', 'Office supplies' and 'Catering for commercial and larger events in concert house'.

The initial results from the project group was included in a report called "Sourcing analysis and strategy for the FM area - Recommendation of scope for DR's coming FM tender" (translated from Danish) and the recommendations were approved by DR's board of directors in spring 2014. Alongside preparing and finalising the report the work with preparing the detailed tender specifications and definitions of SLA's and KPI's had started in the project group with involvement of a larger group of staff including super users from the different departments in DR. This continued during the rest of 2014. The procurement process started with prequalifications in autumn 2014 and finished with tendering and contracting in the second half of 2015. The former I-FM terminated by the end of 2015 , and the new contracts started by 1 January 2016. 


\section{The results of the tendering process}

The tendering covered the 3 bundled service contracts and 7 single service contracts. For the bundled contracts there were 7 prequalified bidders and there were 4-6 bids for each of the contracts. There were possibilities to give combined bids for 'Security and internal service' and 'Cleaning', but none of the two received combined bids won the competition. The result was that the former I-FM provider Coor Service Management won the competition for 'Security and internal service', while the ISS won both the competitions for 'Cleaning' and 'Catering' the same services they were providing to DR before the I-FM contract.

The overall results of the sourcing and procurement process was that DR achieved a total cost reduction of $10-15 \%$. This even though the insourced part of 'building technic' turned out to be more expensive than expected. It turned out that the I-FM provider had been losing money on this service. The quality levels for the new contracts are in general more or less similar to before. During the specification process DR adjusted requirements which was regarded as unnecessarily high and there has been allocated financial reserves for increasing the quality level for specific services, if this turns out to be necessary to increase user satisfaction.

The specification of cleaning was changed from input requirements based on frequents to output based requirements based on the Nordic cleaning standard INSTA 800. For catering the former agreement based on a management fee has been changed to a "restaurant" model based on a frame agreement. The provider is paid a fixed fee per item sold to a fixed price within a specified range of catering offers. The provider has the risk for the amount of procured raw materials and produced food, and the provider thereby has an incentive to sell as much as possible. The provider is free to sell other catering products than the specified range and can decide the price of such offers.

Major changes have been made in the new contracts in relation to simplify the way the performance are measured and monitored. The number of KPI's has been reduced drastically and a clear coherence has been established between SLA's and KPI's and between these and the general contract conditions. To monitor the ongoing performance the SLA's and KPI's have been set up in a Service Performance Dashboard running as a web portal, where all reports on KPI's are monitored in regards to keeping reporting schedule, data and trends as well as actual results of KPI assessments. Joint quality check rounds with participation from DR and each provider now takes place monthly except for cleaning, where they during the I-FM contract took place on quarterly basis, and the new contracts include predefined forms to be used in these check rounds. The contract meetings are now separate for each contract and for the three bundled contracts they include a monthly contract follow-up meeting and a weekly coordination meeting.

One of the main challenges in preparing the new contracts was to define the interfaces between the different contracts. This was for instance the case for handyman tasks and the final solution was to insource these tasks. For other reasons it was also decided to insource "print and copy service' which only concerned two employees. As part of the transition approx. 25 persons were transferred from the I-FM provider to DR concerning 'building technic', including a head of department. Besides, DR employed one more technician. A number of persons were also transferred from the I-FM provider to DR's concert house and the cleaning and catering staff was transferred to ISS. 


\section{ANALYSIS}

\section{The relationship lifecycle and I-FM}

The I-FM contract period was limited to five years due to EU procurement regulation. By the end of year five the contract terminated and - unless the services were all insourced or no longer needed - a public tender had to be arranged beforehand to choose one or more providers based on competitive tendering to take over responsibility for the provision. The same provider could continue, if they won the competition, but that would not be known to the parties earlier during the contract period, so they could not plan with that in mind. This time limit for contracts with public clients clearly limits the possibility to create strategic partnerships with a long term focus with common goals.

Coenen and Nwanna (2014) investigate the relationship lifecycle in FM based on generic lifecycle stages in business to business settings and an empirical study of relationships between private FM clients and providers ongoing for 8-11 years. They divide the relationship lifecycle in FM in three stages; initiation, enhancement and dissolution. This is quite similar to the lifecycle that could be observed in the I-FM contract in DR. It started with an implementation or integration phase, where the new provider should get the service provision into a steady routine. This was intended to take place within the first months or the first half year dependent on the different services. The next phase was development or process optimisation, where improvements should be found and implemented. The provider in their offer described this as part of the incentive agreement and stressed that the operation should be stable, before process optimisation could start. In reality it took up to two years for some services before the development phase could start. The last phase was termination and planning for the termination started after 3 years. This means that the time for process optimisation mostly was the year in the middle of the five year contract period.

The provider was as mentioned earlier obliged to prepare a catalogue each year with proposals for savings that did not reduce service quality. The provider was extremely efficient in finding such proposals according to DR's contract manager and that is also a precondition for them to be able to make a profit on the contract. However, DR was often not asked for consent beforehand, when the provider decided to reduce their staff working on the contract. The incentive agreement also included other types of saving with gain sharing between the DR and the provider, but there were very few such savings.

A main argument for I-FM is one point of contact between client and provider, which should secure clear line of communication and reduce management resources. This was as mentioned earlier far from reality in this case; partly due to the provider's internal organisation in profit centre. Furthermore, the provider had over 250 sub-contractors, which made communication with the people with the professional expertise even more difficult. It also meant that the I-FM provider added a mark-up of $10-15 \%$ on all cost for sub-contractors, which reduces the economic rationale of I-FM. Another main argument for I-FM is that the provider can create synergies between services. Such possibilities are limited, if services are provided by subcontractors. DR's analysis of possible synergies also shows that it is only for few services, where synergies are relevant. The result of DR's tender, where none of the combination bids won, is a further indication of this.

\section{Sourcing models for FM}

A comparison of the relationship types and sourcing models mentioned in the literature review is shown in Table 3 divided according to the classification by Williamson (2008) in market 
based, hybrid and hierarchy based models. The table also include the models used in DR's analyse and the choice of models made by DR. The I-FM contract formerly used by DR is classified as strategic partnering as defined by Ventovuori and Lehtonen (2006) even though the intended real partnership could not be achieved. Compared to the models by Vitasek (2016) the I-FM more resembles the performance based/managed model than the outcome based Vested business model. The new models chosen by DR is seen as a combination of 7 single service market based out-tasking contracts, 3 bundled service hybrid outsourcing contracts that resembles operational partnering as defined by Ventovuori and Lehtonen (2006), and insourcing as a hierarchy based model.

Table 3: Comparison of sourcing models according to classification by Williamson (2008)

\begin{tabular}{|c|c|c|c|c|}
\hline & Market & \multicolumn{2}{|c|}{ Hybrid } & Hierarchy \\
\hline $\begin{array}{l}\text { Hui and Tsang } \\
\text { (2004) }\end{array}$ & Out-tasking & $\begin{array}{l}\text { Outsourcing for cost } \\
\text { efficiency }\end{array}$ & $\begin{array}{l}\text { Outsourcing for } \\
\text { capability }\end{array}$ & Insourcing \\
\hline $\begin{array}{l}\text { Ventovuori } \\
(2006)\end{array}$ & $\begin{array}{l}\text { Arm's length } \\
\text { relationship }\end{array}$ & \multicolumn{2}{|c|}{ Partnering } & $\begin{array}{l}\text { In-house sourcing } \\
\text { In-house } \\
\text { production }\end{array}$ \\
\hline $\begin{array}{l}\text { Ventovuori } \\
\text { (2006) }\end{array}$ & $\begin{array}{l}\text { Arm's length } \\
\text { relationship }\end{array}$ & $\begin{array}{l}\text { Operational } \\
\text { partnering }\end{array}$ & Strategic partnering & $\begin{array}{l}\text { In-house } \\
\text { production }\end{array}$ \\
\hline $\begin{array}{l}\text { Lok and Baldry } \\
\text { (2015) }\end{array}$ & Technical expertise & Service commitment & Common goals & In-house \\
\hline \multirow[t]{2}{*}{ Vitasek (2016) } & Transactional & \multicolumn{2}{|c|}{ Relational } & Investment \\
\hline & $\begin{array}{l}\text { - Basic provider } \\
\text { - Approved provider }\end{array}$ & - Preferred provider & $\begin{array}{l}\text { - Performance } \\
\text { based/ managed } \\
\text { - Vested business }\end{array}$ & $\begin{array}{l}\text { - Shared service } \\
\text { - Equity } \\
\text { partnership }\end{array}$ \\
\hline DR's analysis & Single services & Bundled services & I-FM & $\begin{array}{l}\text { In-house/own } \\
\text { production }\end{array}$ \\
\hline DR's choice & $\begin{array}{l}7 \text { contracts with } 21 \% \\
\text { of former I-FM }\end{array}$ & $\begin{array}{l}3 \text { contracts with } 70 \% \\
\text { of former I-FM }\end{array}$ & & $\begin{array}{l}\text { Insourcing with } \\
9 \% \text { of former I-FM }\end{array}$ \\
\hline
\end{tabular}

The result of the case from DR shows that it is a complex decision to find an appropriate sourcing solution for FM and it indicates that is can be beneficial to combine different sourcing solutions. The choice between outsourcing and insourcing is mainly based on a balance between cost and business risk and the choice of outsourcing versus out-tasking is mainly based on a balance between high economic volume and possibilities to obtain synergies to make contracts attractive by providers versus lowest possible management fee with a short value chain and direct access to service area experts.

Ownership of IT-systems and data

The case also shows that the ownership and responsibility for operating IT-systems for FM is crucial. Because the provider had integrated all services in the IT-system at their headquarters, it turned out to be difficult to insource services during the contract even though that should be possible according to the contract conditions. Integration of the providers and DR's IT systems also turned out to be more difficult due to DR's IT policy. Besides, there is a risk that essential data about buildings and services are lost in a transition from one provider to another provider, if the provider has ownership over and operates IT-systems. Changes of IT-system and transfer of or re-establishing data in any case represent a major switching cost, if the provider is in charge of the IT-systems to manage the service provision. Former research has documented that increased control over data in outsourcing relationships can be an important driver for clients 
to invest in ICT (Scupola, 2012). As part of the change in sourcing, DR decided to buy and operate a comprehensive service portal and take ownership of all data.

The strategic sourcing process compared with the new ISO-standard Compared to the new standard ISO (2016b) the main activities described in the standard can be identified in DR strategic sourcing process. A main difference is that the standard takes the starting point more or less from a 'clean sheet', where you start the process from scratch without a prior history of FM sourcing. This means that in DR's case many aspects did not need indepth consideration, because of the organisation's history of outsourcing. The first two phases of investigating the sourcing strategy in relation to the core business context and identifying current and future needs mostly consisted of the evaluation of the then ongoing I-FM collaboration. Another difference was that the process in DR had less phases and more parallel activities in developing the sourcing and procurement strategy. This also relates to the most essential difference. The standard is based on a sequential process starting with a gradual specification of the demand and needs before investing possible delivery options. In the DR case the delivery options were investigated before making detailed specification of the needs in terms of Service Levels. This turned out to be crucial as the ways needs are specified are depending on the chosen sourcing models. For instance with the choice of an output based cleaning model based on INSTA 800 the service levels for cleaning need to be specified in a completely different way compared to the former frequency based model. The same is the case for catering with the new "restaurant" model compared to the former model based on a management fee.

This represents a serious problem with the sequential model in the standard starting with detailing the demand before investigating sourcing option. Besides that the standard has a sound approach to strategic sourcing being open to combining internal and external service provision. The standard does not include specific analytical tools like those used in the DR case, including among other right-sourcing matrix, synergy matrix, priority triangle, and Krajlic's sourcing model.

\section{DISCUSSION AND CONCLUSION}

The case applies the concept of 'right-sourcing'. This s a concept mostly used by consultants and until now hardly used in scientific research. The international renowned IT-consulting company Gartner on their website presents a toolkit for right-sourcing tool with eight sourcing models and six sourcing options (Gartner, 2016). An example of a definition from another company website says: "Rightsourcing goes beyond outsourcing, ensuring that every core business function - including in-house and supply chain - is delivering maximum value to your organization, based on cost, quality, and expediency. Rightsourcing is finding the right team to do the job better, faster, and at the right price." (Blur Group, 2016). The advantage of the concept is that it removes the discussion from the dichotomy between either outsourcing or inhouse and opens up for a more nuanced discussion with the possibility to combine different sourcing solutions.

The case presented and analysed in this paper shows the relevance of such a more nuanced approach. Based on a thorough analysis the case organisation decided to change the sourcing strategy with insourcing of the most critical building related activities and changing the procurement strategy to 3 bundled service contracts and 7 single service contracts. The choice between outsourcing and insourcing was mainly based on a balance between cost and business 
risk and the choice between outsourcing versus out-tasking was mainly based on a balance between high economic volume and possibilities to obtain synergies to make contracts attractive by providers versus lowest possible management fee with a short value chain and direct access to service area experts. To get attractive offers you need to be an attractive client.

The comparison of the strategic sourcing process in the case organisation and the new ISO standard showed that the process in DR had less phases and more parallel activities in developing the sourcing and procurement strategy. The main problem with the standard is that it is based on a sequential model starting with detailing the demand and needs before investigating sourcing option. The case shows that the ways needs are specified in tender material are depending on the chosen sourcing models. Besides that the standard has a sound approach to strategic sourcing being open to combining internal and external service provisions.

\section{REFERENCES}

Blur Group (2016), Outsourcing versus Rightsourcing - dive into your talent ocean. https://www.blurgroup.com/blogs/size-zero/outsourcing-versus-rightsourcing// (accessed 1809-2016).

Capgemini (2005), More for less - A Nordic Facilities Management Study 2004/2005. Capgemini, Stockholm.

CEN (2006a), Facility Management - Part 1: Terms and definitions, European Standard EN 15221-1. European Committee for Standardization.

CEN (2006b), Facility Management - Part 2: Guidance on how to prepare Facility Management agreements, European Standard EN 15221-5. European Committee for Standardization.

Coenen, C. and Nwanna, P. (2014), "Discovering the Relationship Lifecycle in FM: Phases and Drivers of Client Value Perceptions". Paper in Alexander, K. (ed.) (2014), "Promoting Innovation in FM". Research Papers. Advancing knowledge in FM. International Journal of Facilities Management, EuroFM Journal. March 2014.

Gartner (2016), Toolkit: How to Choose the Right Sourcing Models, Options and Locations. https:/www.gartner.com/doc/502282/toolkit-choose-right-sourcing-models (accessed 1809-2016).

Hui, E.Y.Y. and Tsang, A.H.C. (2004), "Sourcing strategies of facilities management”, Journal of Quality in Maintenance Engi neering. Vol. 10, No. 2, pp. 85-92.

Ikediashi, D.I, and Ogunlana, S.O. and Boateng, P. (2014), "Determinants of outsourcing decision for facilities management (FM) services provision”, Facilities, Viol 32, No. 9/10, pp. 472-489.

ISO (2016a), Facility Management - Part 1: Terms and definition. International Standard ISO 41011. International Organization for Standardization.

ISO (2016b), Facility Management - Part 2: Guidance on how to prepare Facility Management agreements. International Standard ISO 41012. International Organization for Standardization.

Jensen, P.A. (2012), International coordination of Facilities Management in multinational corporations. Proceeding of International Congress on Construction Management Research CIB International MCRP Conference, Montreal 26-29 June 2012.Jensen, P.A. (2008), "The Origin and Constitution of Facilities Management as an Integrated Corporate Function", Facilities, Vol. 26, No. 13/14, pp. 490-500, 2008. 
Krajlic, P. (1983): "Puchasing must become supply management". Harvard Business Review, September 1983.

Lok, K.A. and Baldry, D. (2015), "Facilities management outsourcing relationships in the higher education institutes", Facilities, Vol. 33, No. 13/14, pp. 819-848.

Plane, C.V. and Green, A.N. (2011), "Buyer-supplier collaboration: the aim of FM procurement?", Facilities, Vol. 30, No. 3/4, pp. 152-163.

Redlein, A. and Zobl, M. (2014), Outsourcing: a cost-saving approach in FM?, Proceedings of CIB FM Conference, 21-23 may 2014. Technical University of Denmark.

Scupola, A. (2012), "ICT Adoption in Facilities Management Supply Chain: The Case of Denmark." Journal of Global Information Technology Management, Vol. 5, No. 1, pp. 5378.

Teichmann, S. (2009), "FM market size in Europe", European FM Insight, Issue 11, September 2009), pp. 5-7.

Van der Spil, T. (2013): "Facilities market contracts again - Survey of the Dutch FM market published", European FM Insight, Issue 24, March 2103, pp. 5-6.

Ventovuori, T. (2006) "Elements of sourcing strategies in FM services - a multiple case study", International Journal of Strategic Property Management. Vol. 10, No. 4, pp. 249-267.

Ventovuori, T. (2007), Elements of sourcing strategy in FM services - Decision categories and choices. Doctoral Dissertaion. Helsinki University of Technology

Ventovuori, T. and Lehtonen, T. (2006), "Alternative models for the management of FM services - An empirical investigation", Journal of Corporate Real Estate, Vol. 8, No. 2, pp 73-90.

Williamson, O.E. (2008), "Outsourcing: transaction cost economics and supply chain management", Journal of Supply Chain Management, Vol. 44, No. 2, pp. 5-16. 